\title{
CONSTANT SOFT TISSUE DISTANCE MODEL IN PREGNANCY
}

\author{
PAUL L. CARSON, JONATHAN M. RUBIN AND EDWARD H. CHIANG
}

Division of Radiological Physics

University of Michigan Hospitals

Ann Arbor, Michigan 48109-0553, USA

\section{INTRODUCTION}

The thickness of various underlying tissue layers were measured at locations where the overall thickness and, therefore, the ultrasound attenuation prior to the fetus appeared minimized. Identification of a worst case, or a small group of potentially high exposure situations, is necessary for the optimal design and use of ultrasound equipment. Appropriate measurements in these cases allow calculation of estimated intensities in situ for comparison with future actual measurements. While other types of examinations, for example, intraoperative imaging with a saline or water standoff, provide even less overlying attenuation, obstetrical applications are more numerous and warrant attention.

Earlier estimates of attenuation of tissues overlying the fetus centered on first trimester pregnancy, and were summarized by the NCRP (1983). Those measurements used phase-sensitive ultrasound receivers and yielded relatively high transducer-to-gestational sac pressure losses. Attenuation estimates in the first and last trimester were suggested by Carson (1988), based on an informal search of worst cases in a few clinical examinations. These and the NCRP estimates yielded a total minimum attenuation at $3.5 \mathrm{MHz}$ of $3.9 \mathrm{~dB}$ in the first trimester and $1.6 \mathrm{~dB}$ in the third trimester, from overlying tissue of thicknesses of 2.6 and $1.0 \mathrm{~cm}$, respectively. These estimates, being lower than earlier estimates and measurements, suggested a need for specific worst case measurements. The second trimester cases was studied in this current work because of the expected fetal sensitivity to thermal and other insults at this stage and because the overlying tissue was expected to be thin relative to the first trimester.

\section{METHODS}

Ultrasound imaging for guidance of genetic amniocentesis provided a set of 22 patients in a limited, 15-20 week range of gestational ages. Subjects were selected randomly, independent of maternal size. Imaging was performed with a conventional sector scanner (Picker Artis, with a 5 or 3.5 MHz transducer) and a standoff. Because of the known differences in attenuation coefficients, tissues were grouped into the following categories: Skin; subcutaneous fat; abdominal muscle or linea alba and fatty fascia (preperitoneal fat); and myometrium. The placenta and bladder were not included because they will not, in the worst cases, lie in the prefetal imaging path.

To evaluate the effects of the standoff, the same plane was imaged in several patients with a linear array and with the sector scanner, with and without a standoff. Total thicknesses measured with the standoff and the linear array agreed within $+1 \mathrm{~mm}$, while direct contact sector scanning depressed the thickness of overlying tissues by an average of $3.5 \mathrm{~mm}$ more than the other two methods.

Attenuation coefficients used to calculate attenuation in the various tissue layers were the same as those employed by the NCRP (1983) and Carson

(1988) except that skin is added separately here. In $\mathrm{dBcm}^{-1} \mathrm{MHz}^{-2}$, they were: skin - 1.5; subcutaneous fat - 0.46; abdominal (skeletal) muscle 0.51 ; preperitoneal fascia - 0.51; myometrium (smooth muscle) - 0.29 .

Fig. 1 shows individual measurements of thickness of overlying tissue layers and total overlying tissue thicknesses as a function of maternal weight. Linear regressions are shown as the solid lines. The one case at $97 \mathrm{~kg}$ was not included in the linear regressions, because the data suggested that different anatomical relations may exist in this obese case. 


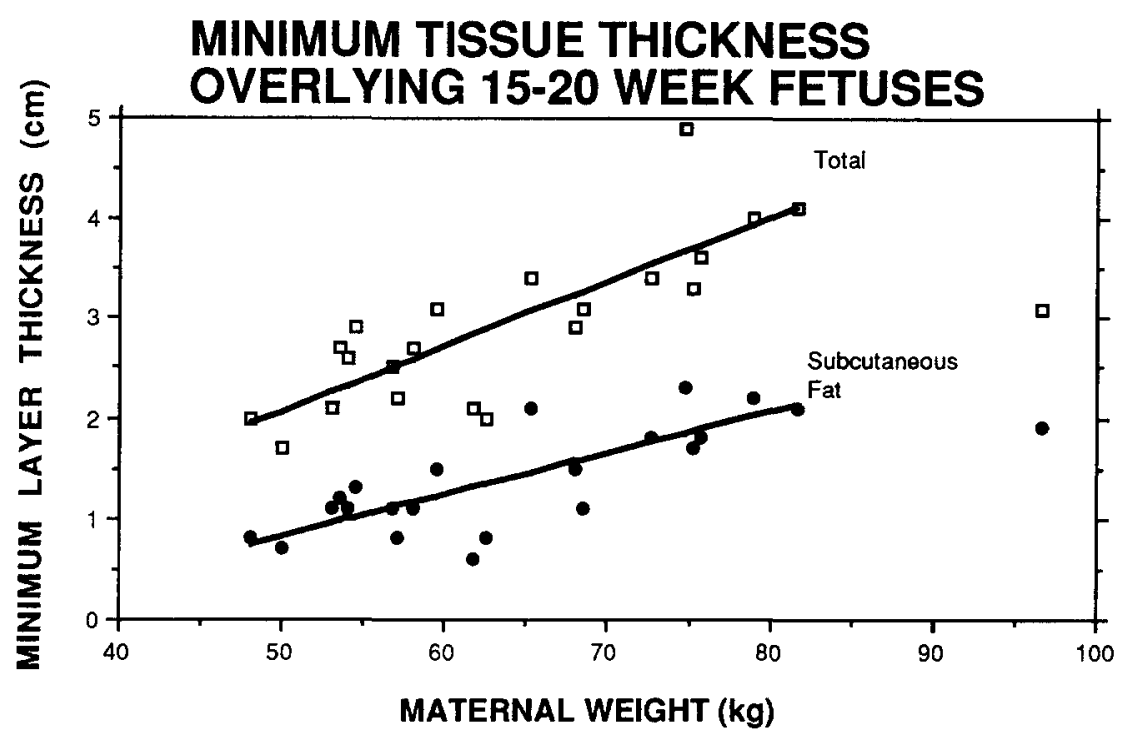

Figure 1. Thicknesses as function of maternal weight for subcutaneous fat overlying the fetus and for the total of four layers.

The minimum path length of attenuating tissue was only $1.7 \mathrm{~cm}$,

corresponding to an attenuation of $0.8 \mathrm{dBcm}^{-1} \mathrm{MHz}^{-1}$, or $2.8 \mathrm{~dB}$ at $3.5 \mathrm{MHz}$. A skin thickness of $1.3 \mathrm{~mm}$ was assumed for this minimum, while 2 mm was assumed for all other data points. Fig. 2 shows the calculated minimum attenuation at $3.5 \mathrm{MHz}$ for individuals as a function of maternal weight, Calculated attenuation correlates reasonably well with maternal weight $\left(R^{2}\right.$ $=0.68)$, and the latter might be used in some cases to estimate the former. The best fit linear regression shown in Fig. 2 as the central line, is given by: Attenuation $(\mathrm{dB})=0.10 \mathrm{x}$ weight $(\mathrm{kg})-1.5$. The 958 prediction limits are also plotted in Fig. 2. The lower 95\% prediction limit is given approximately by: Attenuation $=0.10 \times$ Maternal weight -3.3 . Attenuation correlated almost as well $\left(\mathrm{R}^{2}=0.57\right)$ with maternal anterior-posterior diameter.

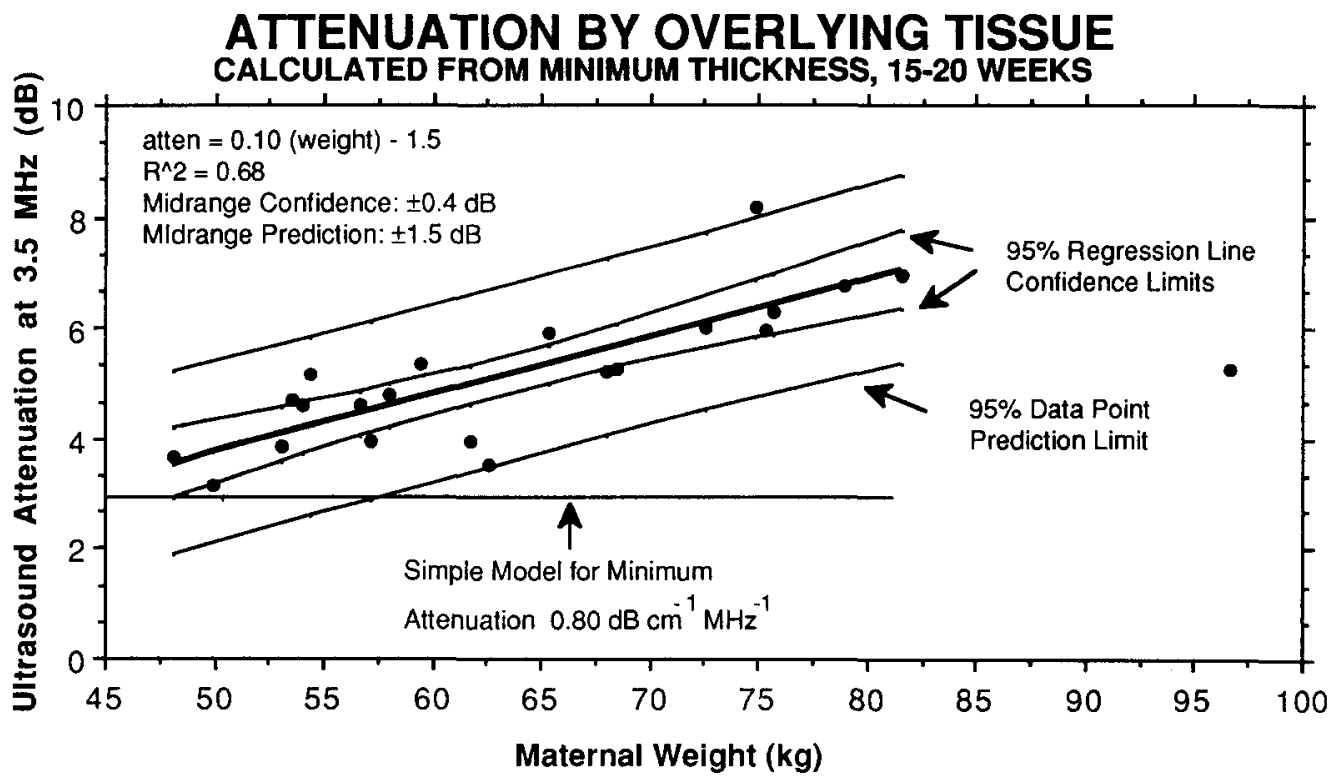

Figure 2. Calculated attenuation by overlying tissues is shown as a function of maternal weight 


\section{ACKNOWLEDGEMENT}

This work was supported in part from the PHS Grant 5R01 HD17243, National Institute for Human Growth and Development.

\section{REFERENCES}

Carson, P. L. Medical Ultrasound Fields and Exposure Measurements, Procs. Twenty-Second Annual Meeting of NCRP, NCRP, Bethesda, MD., 287-307;1988.

NCRP, Biological Effects of Ultrasound; Mechanisms and Clinical Implications, NCRP Report No. 74. National Council on Radiation protection and Measurement, Bethesda, MD.;1983. 